\title{
Trabalho docente, readaptação e saúde: a experiência dos professores de uma universidade pública
}

I ${ }^{1}$ Ana Paula Santos Arbex, ${ }^{2}$ Katia Reis Souza, ${ }^{3}$ André Luis Oliveira Mendonça I

Resumo: O objetivo principal deste artigo é analisar, pelo ângulo dos próprios trabalhadores, os sentidos da readaptação na vida dos professores de uma universidade pública, sob o enfoque metodológico da pesquisa qualitativa. Participaram do estudo oito professores readaptados com vínculo estável na universidade, sendo que dois pertenciam ao colégio de aplicação. Quanto à discussão do material, optouse pelo método de análise do discurso, objetivando interpretar, a partir de sua própria fala e vivência, como os docentes lidam com o fato de serem readaptados. As principais categorias empíricas advindas das análises das falas foram: "Você tem que correr atrás para que seu trabalho seja publicado e ainda ministrar e preparar as aulas"; "A readaptação foi favorável para minha saúde porque saí da sala de aula"; "Aqui há falta crônica de professores"; "O pior do processo de readaptação é o tratamento dado pelos colegas"; "Na perícia central você é muito maltratado". Concluiu-se que a readaptação funcional é um processo gerado por condições coletivas de trabalho como, por exemplo, a sobrecarga de aulas, o que exige a necessidade de intervençōes institucionais de caráter coletivo para a promoção de ambientes laborais mais saudáveis.

> Palavras-chave: readaptação no trabalho; trabalho docente; saúde do trabalhador; sala de aula; perícia médica.
1 Graduação em Serviço Social pela UERJ e especialista em Saúde do Trabalhador pelo Centro de Estudos da Saúde do Trabalhador e Ecologia Humana, Escola Nacional de Saúde Pública (CESTEH/Ensp/Fiocruz). Endereço eletrônico: apsa73@gmail.com

${ }^{2}$ Mestre em Educação e Saúde pelo Nutes-UFRJ; doutora em Saúde Pública pela Fiocruz; pesquisadora do CESTEH/Ensp/ Fiocruz. Endereço eletrônico: katreis@ensp.fiocruz.br

${ }^{3}$ Pós-Doutorando do IMS-UERJ; mestre e doutor em Filosofia pela UERJ. Endereço eletrônico: andre.o.mendonca@ibest.com.br
Recebido em: 09/08/2012. Aprovado em: 13/03/2013. 


\section{Introdução}

O mundo do trabalho tem sofrido profundas mudanças com o processo de globalização e a nova ordem estabelecida nas relações entre capital e trabalho. Segundo Hardt e Negri (2005), distingue-se, nesse cenário, o fato de que o trabalho industrial perdeu sua hegemonia, ganhando notoriedade o "trabalho imaterial", ou seja, trabalho que cria produtos imateriais, como o conhecimento, a informação, a comunicação e as relações afetivas. Nesse sentido, o paradigma do trabalho imaterial permite novas lentes conceituais de interpretação dos modos atuais de exploração do trabalho, pois são formas de produção para as quais não se deve mais adotar como referência os padrões convencionais do trabalho fabril e fordista. No caso específico dos docentes, estes são reconhecidamente trabalhadores intelectuais na área de serviços (LIMA; LIMA-FILHO, 2009), na qual, devido à imaterialidade do trabalho, muitos aspectos da atividade docente não são vistos.

Em estudo realizado por Alvarez (2004), a autora assegura que existe um desconhecimento a respeito do processo de trabalho docente universitário e das condições materiais em que ele se realiza. Constatou-se que essa dimensão invisível do trabalho acadêmico possui uma interface com um sentimento de nãoreconhecimento social por parte dos professores, podendo ocasionar ressonâncias no seu quadro psíquico. Ademais, segundo a autora, não se pode falar em jornada de trabalho formal para o docente universitário, pois essa categoria trabalha à noite, nos feriados e finais de semana. De fato, alguns estudos confirmam a expansão do tempo de trabalho do professor, e não somente de professores universitários, para todo o tempo de descanso e de lazer (BRITO; ATHAYDE, 2003; GASPARINI; BARRETO; ASSUNÇÃO, 2005). Trata-se do que alguns autores denominam de intensificação do trabalho docente (LEMOS, 2011; ASSUNÇÃO; OLIVEIRA; 2009).

Nota-se, então, que o serviço público, e nele o trabalho docente, não ficaram incólumes às transformações ocorridas no mundo do trabalho, pois a precarização das condiçõos de trabalho e de saúde afetaram social e psiquicamente esses trabalhadores. Lacaz (2010) afirma que a impregnação da lógica capitalista e da reestruturação produtiva neoliberal, identificada como capitalismo organizacional e acadêmico nos espaços da universidade pública, produz a precarização das condições do trabalho docente. Como desdobramento desta nova forma de trabalhar - que impõe a competição e o individualismo, 
entre outras características próprias do capitalismo -, ocorrem repercussōes na saúde dos trabalhadores, especialmente na esfera psicoafetiva e da saúde mental.

Percebe-se, então, que a realidade enfrentada no cotidiano laboral impõe efeitos no perfil epidemiológico das doenças relacionadas ao trabalho dos professores, o que leva à pertinência de um debate renovado acerca da gênese dessas doenças e de sua gravidade (TOLDRÁ et al., 2010). Dentro desse contexto, a readaptação no trabalho é um dos resultados dos efeitos das condições de trabalho na saúde dos professores.

Em estudo realizado por Nunes, Brito e Athayde (2001) com trabalhadores de escola da rede pública de ensino do Estado do Rio de Janeiro, os autores constataram que não existe um sistema, no setor público, para investigar as relações entre saúde e trabalho, conhecer o trabalho efetivamente realizado e, quando oportuno, intervir sobre as fontes de nocividade.

Nos termos da lei, readaptação profissional "é a investidura do servidor em cargo de atribuições e responsabilidades compatíveis com a limitação que tenha sofrido em sua capacidade física ou mental verificada em inspeção médica" (BRASIL, 1990; RIO DE JANEIRO, 1979). O principal critério para a readaptação do professor é a avaliação pericial da sua capacidade laborativa. A readaptação dependerá sempre de prévia inspeção realizada por junta médica (RIO DE JANEIRO, 1979). Deste modo, a junta médica oficial é responsável pela indicação das restrições das atividades laborais de cada trabalhador, caso a caso, não existindo um protocolo único para a readaptação docente, exceto pelo fato de ser realizada sempre "extraclasse", ou seja, o professor readaptado (pertencente à UERJ) deverá ser afastado das atividades de sala de aula.

Trata-se de um direito do servidor público estatutário, diferenciando-se da reabilitação dos trabalhadores (do setor privado) vinculados ao INSS. De todo modo, a reinserção no trabalho, seja pela readaptação ou reabilitação, possui importante significado para o trabalhador a ser compreendido, pois seu afastamento por motivo de saúde gera uma nova condição laboral, social e simbólica - a de readaptado -, levando-o a vivenciar relações singulares sucedidas no próprio ambiente de trabalho, além de sentimentos de perda, frustração e fracasso (NUNES; BRITO; ATHAYDE, 2001).

Diante dessas assertivas, organizamos este artigo em três seções, afora esta introdução, a saber: na segunda parte, apresentamos os fundamentos filosóficos 
e conceituais do estudo; nela apresentamos os principais pressupostos teóricos do campo da saúde do trabalhador, do materialismo histórico, da concepção "vitalista" de saúde, da ergonomia da atividade e da psicodinâmica do trabalho, já que consideramos essas abordagens complementares para a construção de uma concepção relacional entre trabalho e saúde. $\mathrm{Na}$ terceira seção, descrevemos a metodologia do estudo. Quanto à quarta seção, apresentamos os resultados de nossa pesquisa de campo e as análises interpretativas dos materiais empíricos. Por fim, nas considerações finais, concluímos que a readaptação funcional é um processo gerado por condições coletivas de trabalho - e.g.: sobrecarga de aulas -, o que exige mudanças com a participação ativa dos trabalhadores e suas organizações. ${ }^{1}$

\section{Saúde do trabalhador e readaptação do professor}

A perspectiva do campo da saúde do trabalhador amplia o ponto de vista acadêmico, político e institucional da Saúde Coletiva, através da demarcação do processo saúde e doença dos diversos grupos humanos, em sua relação com o trabalho, contrapondo-se à base conceitual das concepções hegemônicas sobre a relação trabalho-saúde (da medicina do trabalho e da saúde ocupacional). Essa perspectiva transcende o marco do direito previdenciário-trabalhista e coloca em destaque o lado humano do trabalho (MINAYO; GOMEZ, 2011).

Nessa linhagem, servem de fundamento filosófico as análises substantivas de Marx sobre o trabalho, colocando em destaque seu núcleo fundamental acerca da produção da vida material: o trabalho não deriva somente da necessidade de satisfação biológica para a reprodução da vida, mas, sobretudo, de uma satisfação social, de realização humana que possibilita a produção de valores e de ideias (MARX, 1974).

Por esse ângulo teórico, interpreta-se que é no modo de produção capitalista que o trabalho deixa de ser liberdade de realização de si mesmo, passando a ser estranho e alienado (MARX, 1974). De acordo com Dejours (2004), pode-se perceber a centralidade do trabalho, na construção da identidade humana e na sua saúde, como fonte de sofrimento e prazer. $\mathrm{O}$ trabalho pode ser um gerador de saúde ou, ao contrário, um constrangimento patogênico. $\mathrm{O}$ trabalho jamais é neutro. Ou joga a favor da saúde ou, pelo contrário, contribui para sua desestabilização e empurra o sujeito para a descompensação (DEJOURS, 2004, p. 138). 
Em O normal e o patológico, Canguilhem (1990) desenvolve o argumento

de que a vida se refaz pela instauração de novas normas, frente às adversidades do meio. A normalidade consiste, assim, na capacidade de adaptação e de variação do organismo às mudanças circunstanciais do meio externo e interno (PORTOCARRERO, 2009). Canguilhem busca pensar o adoecimento e a saúde como produção de condições de existência e considerando seu caráter de imprevisibilidade. Dessa forma, a presença de uma patologia não estabelece a linha divisória entre o normal e o patológico, mas pode representar novos sentidos desse adoecimento e os efeitos produzidos na vida do sujeito (RAMOS; TITTONI; NARDI, 2008). Questiona-se, então, a racionalidade do modelo hegemônico do campo da saúde: o biomédico. No modelo biomédico, predomina a perspectiva que favorece intervençôes técnicas, mas pobres do ponto de vista afetivo e subjetivo (CZERESNIA, 2010).

De modo complementar, a perspectiva teórica do campo da saúde do trabalhador serve de base a uma reformulação no atual modo de conceber o trabalho e suas relações com a saúde, começando por conhecer a situação do trabalhador readaptado pelo ângulo do próprio readaptado, valorizando a sua experiência e o seu conhecimento (ODDONE et al., 1986).

Convergente com a Saúde do Trabalhador, a ergonomia oriunda da escola franco-belga, propõe uma racionalidade diferenciada, segundo a qual as principais causas dos problemas que afetam os trabalhadores estão na inadequação do trabalho em relação ao homem. (WISNER, 2004; GUÉRIN et al., 2001). Dessa forma, essa abordagem se opõe completamente à ideia de adaptação do homem ao trabalho. Esse pressuposto contribui para se colocar a questão a respeito da readaptação no trabalho no seu devido lugar: "readaptar o quê?”, e não "readaptar a quem?” (GOMES, 2011).

Complementarmente, a perspectiva ergológica (SCHWARTZ; DURRIVE, 2007) propõe o conhecimento das situaçôes reais de trabalho para, então, compreendermos os processos de adaptação ou de inadaptação ao trabalho. De acordo com Duraffourg (2007), aqueles que não se adaptam ao trabalho, que resistem, tornam-se literalmente "inadaptados" e são, muito frequentemente, culpabilizados. Desse modo, mascara-se a realidade dos problemas do trabalho e das condições às quais as pessoas estão submetidas no trabalho, deplorando-se as consequências nefastas sobre a saúde (DURAFFOURG, 2007). 
Neste artigo, desenvolvemos o argumento de acordo com o qual existe um importante aspecto a ser considerado nos processos de readaptação no trabalho, confirmado pela escassa literatura sobre o tema (BATISTA; JULIANI; AYRES, 2010; FANTINI; SILVEIRA; ROCCA, 2010; MEDEIROS; BARRETO; ASSUNÇÃO, 2006), que diz respeito às suas implicações na subjetividade dos trabalhadores: a readaptação não pode ser reduzida apenas aos distúrbios clínicos, nos quais a causa do adoecimento fica centrada nos fatores biomédicos. Ela é um processo complexo, que compromete a vida das pessoas. Portanto, fazse necessário compreender o sentido do afastamento do trabalho levando-se em conta os efeitos do processo de ruptura sofrido pelo trabalhador.

Ao pensarmos a readaptação e o afastamento do trabalho não só como ameaça de ruptura, podemos apontar sua potencialidade enquanto resistência, uma vez que a condição de "estar fora" pode permitir ao trabalhador a reinvenção de outros fluxos que produzem novos sentidos para reconfiguraçōes do trabalho cotidiano (RAMOS; TITTONI; NARDI, 2008). Em face dessa problemática, tem-se como pergunta norteadora central: qual o sentido da readaptação na vida dos professores afastados de suas funções no trabalho?

Acreditamos que a relevância do estudo reside na diminuta e quase ausentes pesquisas e publicações a respeito da temática "readaptação de professores de universidades". Nosso objetivo principal consiste em analisar, pelo ângulo do trabalhador, os sentidos da readaptação na vida dos professores com vistas a romper com a lógica da naturalização das doenças relacionadas ao trabalho docente.

\section{Metodologia}

O presente estudo foi desenvolvido na Universidade do Estado do Rio de Janeiro (UERJ), localizada no bairro Maracanã na cidade do Rio de Janeiro. O órgão responsável pela execução, planejamento e informações a respeito da política de Saúde do Trabalhador e da readaptação é o Departamento de Segurança e Saúde no Trabalho (DESSAUDE).

Participaram do estudo oito professores readaptados, o que significa dizer que são docentes que estão afastados de suas funções originais ou tiveram suas atividades laborais alteradas devido à sua situação de saúde. Por conseguinte, o critério de inclusão era pertencer ao quadro de professores da Universidade e 
estar formalmente readaptado. Optou-se por estudar a readaptação através de entrevistas individuais com professores que estivessem há mais de dois anos em situação de readaptação, acompanhados institucionalmente pelo DESSAUDE. Os docentes participantes da pesquisa foram selecionados através do critério de acessibilidade, sem distinção de lotação, pois nosso intento principal é conhecer o ponto de vista e a experiência de professores readaptados por intermédio de relatos diversos de experiência. Cabe a observação de que dois docentes, dos oito entrevistados, pertencem ao quadro de professores do Colégio de Aplicação da universidade, Cap-Uerj. ${ }^{2}$ Optamos por mantê-los em nossa análise, devido ao fato de que, nos depoimentos, esses docentes mostraram similaridades em relação às vivências dos professores universitários; principalmente no tocante aos fatores da organização do trabalho que geram sobrecarga e, consequentemente, levam os docentes ao adoecimento. Ademais, as falas dos professores do CAP ampliaram, sem dúvida, nossa compreensão em relação à vivência da readaptação e dos problemas do trabalho docente na universidade. Assim, usamos um artifício para diferenciação dos grupos de entrevistados, qual seja: os professores da universidade serão identificados como PU (professores da universidade), enquanto os docentes do colégio de aplicação serão referidos pela abreviação PC (professores do Cap).

Destarte, desenvolvemos um estudo exploratório de caráter qualitativo, que, do ponto de vista epistemológico, permite incorporar, teoricamente e na prática, a evidência empírica de que a saúde e a doença não se reduzem a uma experiência orgânica, biológica e externa aos sujeitos, pois o corpo humano está atravessado pelas determinações das condições, situações e estilos de vida (MINAYO, 2004). $\mathrm{O}$ pressuposto fundamental é o de que a ação humana é radicalmente subjetiva. O comportamento humano, ao contrário dos fenômenos naturais, não pode ser descrito e muito menos explicado apenas com base nas suas características exteriores ou, somente, por meio de dados estatísticos e matemáticos, uma vez que o mesmo ato pode corresponder a sentidos muito diferentes (SANTOS, 1997).

Quanto à técnica de pesquisa adotada, realizaram-se entrevistas individuais e semiestruturadas, com roteiro de perguntas abertas. A partir das entrevistas, foi realizada a análise do material, tendo como base a Análise do Discurso, seguindo uma tradição dos estudos argumentativos e interpretativos. Segundo Gill (2003), o discurso é “uma forma de ação” e uma "prática social”; através 
da análise de discurso, "pode se ver a vida social como sendo caracterizada por conflitos de vários tipos" (GILL, 2003, p. 250). Por conseguinte, o texto se torna uma unidade complexa de significações.

Organizamos a apresentação de nossas categorias iniciando cada bloco de análise com trechos de discursos retirados das entrevistas com os professores. Trata-se de uma forma de ordenação dos nossos resultados, realçando o ponto de vista dos próprios trabalhadores. As principais categorias empíricas advindas das análises das falas foram: "você tem que correr atrás para que seu trabalho seja publicado e ainda ministrar e preparar as aulas"; "A readaptação foi favorável para minha saúde porque saí da sala de aula"; "aqui há falta crônica de professores"; "O pior do processo de readaptação é o tratamento dado pelos colegas"; "Na perícia central você é muito maltratado”.

A pesquisa foi conduzida dentro de padrões éticos dispostos na Resolução CONEP no 196/96 e foi aprovada pelo Comitê de Ética em Pesquisa da ENSP/ FIOCRUZ - CEP/ENSP no 135/11, em 06/07/2011.

\section{Resultados e discussão}

\section{“...você tem que correr atrás para que seu trabalho seja publicado [...] e ainda ministrar e preparar as aulas"}

Porque você tem as metas do Boletim de Produção Acadêmica, eles vão ao Lattes
abrem o currículo e capturam de lá o que você produziu nos últimos três anos; se
você atingir as metas da pontuação que eles deram, e que a cada dia está mais difícil
de atingir, ganha a bolsa. A tabela diz o mínimo que a pessoa tem que produzir por
ano. Resumo hoje não vale mais nada, a participação em Congresso vale, mas só a
publicação do trabalho completo. Você tem que correr atrás para que seu trabalho
seja publicado; então, é altamente desgastante, e ainda ministrar e preparar as aulas.
(Professor 1 - PC).

A fala de um professor do CAP-Uerj a respeito do desgaste decorrente das exigências das atividades de ensino e pesquisa denota aspectos similares ao trabalho de professores que exercem suas atividades em universidades. No caso específico dos docentes da UERJ, é preciso destacar, como citado pelo entrevistado, o recebimento de uma "bolsa" de produtividade. Trata-se de um programa exclusivo desta universidade denominado Prociência (Programa de Incentivo à Produção Científica, Técnica e Artística) que se destina a promover 
a produção científica por meio da concessão de uma bolsa especial de dedicação

exclusiva. $\mathrm{O}$ docente incluído no Prociência receberá uma bolsa de pesquisa cujo valor será equivalente a 70\% do vencimento-base (UERJ, 2010).

Tais informações nos levam a constatar um cenário que propicia a competitividade interna entre os docentes, já que de cerca dos 2.100 professores da universidade, apenas 400 (aproximadamente) receberão a referida dotação. Os readaptados, por sofrerem os efeitos da restrição laboral - como o afastamento de sala de aula -, acabam tendo um declínio de sua pontuação no processo de avaliação do Prociência, pois estar ativo lecionando é um critério para a concessão da bolsa, conforme a ponderação deste professor:

Eu tenho a bolsa do Prociência; antes de ser readaptado eu ficava sempre entre os primeiros colocados, como deixei de dar aulas por causa da readaptação, isso fez com que meus pontos caíssem muito na avaliação para concessão da bolsa. Na última avaliação eu fiquei em penúltimo lugar, apesar de ter aumentado a produção científica. A saída da sala de aula diminuiu a pontuação. Por isso esse mecanismo de exigências deve ser adaptado a casos como o meu, senão o professor pode acabar perdendo a bolsa de pesquisa (Professor 4 - PU).

Constatamos, a partir da observação do professor entrevistado, que o docente readaptado, além de conviver com as limitações laborais devido a sua situação de saúde, deve submeter-se às regras da produção acadêmica, em condiçóes de igualdade com os demais docentes. Neste ponto chama atenção a necessidade de formulação de políticas adequadas à saúde e ao trabalho de quem se encontra readaptado em universidades públicas, pois são conhecidas as atuais exigências do trabalho nessas instituições. Segundo Mancebo (2007), verifica-se no cotidiano universitário a instalação de horários atípicos e a aceleração no desempenho das atividades, afetando em cheio a produção docente e reduzindo o tempo de convivência, bem como o campo coletivo de criação. Por outro lado, de acordo com Vieira, Van Bellen e Fialho (2006), cada universidade é uma realidade, um mundo à parte, um campo acadêmico que gera suas próprias forças. Portanto, cada universidade deve promover as mudanças que entender serem mais bem adequadas a sua realidade.

É necessário analisar com cuidado o sentido da atividade em sala de aula, visto que ela é uma das categorias sobressalentes nas falas dos professores readaptados:

Esse trabalho me gratifica enquanto profissional, porque eu ainda oriento alunos, embora poucos, e, como eu saí da sala de aula, aumentaram minha produção científica e 
publicações. Isso é um aspecto muito positivo, porque por eu estar nesse laboratório fui, de certa forma, solicitado a escrever esses artigos e publicá-los; não foi difícil de atender porque era uma conseqüência do que eu vinha fazendo no trabalho. (Professor 8 - PU).

Não obstante, deve-se estar ciente de que, embora os docentes estejam sofrendo com o excesso de exigências acadêmicas (BOSI, 2011; MANCEBO, 2007), a atividade de escrever artigos é reconhecidamente importante e percebida como prazerosa por parte de alguns docentes entrevistados. Percebe-se que a queixa central, presente aos discursos dos professores da UERJ, refere-se à soma de todas as atividades docentes que geram, ao fim, sobrecarga de trabalho. Note ainda que na fala anterior, a atividade de escrever e publicar artigos está também relacionada ao sentido de uma capacidade de continuar ativo, obtendo reconhecimento entre seus pares. De acordo com Luz (2005), a "produção" de artigos pode ser uma categoria que atua positiva ou negativamente, desde que "sob ritmo próprio" e com ampla liberdade: é um fator positivo, pois é pressuposto para a inovação e a criação e é o que move o progresso científico, base da ciência moderna; quanto ao aspecto negativo, é que essa produtividade, sem liberdade e sem ritmo próprio, incide sobre os "produtores" toda a sobrecarga de trabalho. No entanto, de acordo com Dejours (2004), os homens não estão passivos frente à organização do trabalho, pois são capazes de se proteger, elaborando defesas que abrandam o sofrimento.

\section{"A readaptação foi favorável para minha saúde porque sai da sala de aula"}

Outro ponto que se destaca, a partir da análise das falas dos entrevistados, diz respeito à readaptação do docente da UERJ ser extraclasse, ou fora da sala de aula, e como essa situação é percebida pelos professores:

A readaptação foi favorável para minha saúde porque saí da sala de aula que é muito desgastante. Ser readaptado significa continuar produzindo, deixar a parte do trabalho pesado, de carregar o piano [...] não naquele ritmo alucinante: tinha que produzir (artigos) e mais o tempo dentro de sala de aula [...] então o fato é que eu ter saído de sala de aula, depois de trinta anos de trabalho, pra mim foi muito positivo. (Professor 1 - PC).

Segundo o estudo de Sampaio e Marin (2004) a respeito da educação básica, verifica-se, no Brasil, uma queixa constante dos professores quanto ao aspecto do trabalho na sala de aula. Situações como organização de turmas excessivamente numerosas, disciplina e controle de turma concorrem para o desestímulo e para o adoecimento no trabalho. A esse respeito, Neves e Silva (2006) mencionam o 
caso de professoras, também do ensino básico, que passaram a desenvolver açōes reativas, devido à "saturação emocional". Aquilo que um dia foi motivo de prazer - a relação com os alunos - anos depois deixa de ser algo estimulante. Nesses estudos, embora o contexto laboral seja diverso ao deste artigo, as autoras fizeram menção a problemas semelhantes ao trabalho docente universitário, tais como: superposição das atividades que o professor tem de desenvolver, como o apoio e enriquecimento das aulas, as atividades de correção de trabalhos de alunos, apoio aos alunos nas atividades extracurriculares e de formação em serviço para os próprios professores.

De acordo com Quadros et al. (2010), o gerenciamento da sala de aula é uma tarefa que precisa ser mais bem entendida, tanto nas instituiçôes de Educação Básica quanto nas de Ensino Superior e, por isso, mais discutida nos cursos de formação de professores. Para os autores, a assimetria presente na sala de aula, que privilegia os professores em relação aos estudantes, deve promover a discussão de uma agenda/contrato, de forma a se tornarem mais explícitos os objetivos a serem compartilhados.

Contudo, o ponto que queremos realçar é que, na fala do professor, a readaptação é interpretada como positiva, pois ele pôde afastar-se da sala de aula. Verifica-se, no entanto, uma ausência de crítica a respeito do processo de trabalho docente como fator de adoecimento, cabendo avaliar até que ponto a readaptação e o afastamento da sala de aula funcionariam como estratégia defensiva contra o sofrimento no trabalho (DEJOURS, 2004), no sentido de tornar ameno o mal estar laboral, mas sem uma solução para a causa dos problemas de saúde dos professores.

Eu consegui voltar a trabalhar bem devagarzinho, aos poucos, assim foi aumentando o grupo de alunos, até hoje só consigo no máximo ter quatro alunos em volta de mim; mais do que isso, já fico agitada e tonta. (Professor 4 - PU).

De acordo com Gasparini, Barreto e Assunção (2005), quanto mais alunos e mais turmas, maior vai ser o volume de trabalho e maior o esforço intelectual do professor. O número excessivo de alunos por turma foi apontado pelos professores entrevistados como um dos fatores de sobrecarga ao trabalho, resultando em efeitos para a saúde do profissional, tais como agitação, estresse e irritação.

A readaptação funcional me proporciona trabalhar com número menor de alunos, continuo produzindo, só que com muito menos estresse, do que com grupos grandes de alunos. (Professor 2 - PC). 
Para Carlotto (2004), os fatores de estresse do trabalho docente, se persistentes, podem levar à Síndrome de Burnout. A ocorrência de burnout em professores é considerada atualmente um problema social de extrema relevância. Segundo Sousa e Mendonça (2009), ela é consequência de reaçôes a fontes de estresse ocupacional que se acumulam. Para Carlotto e Câmara (2008), a impossibilidade de mudança estrutural nas instituições de ensino, para os professores, pode levar à utilização da estratégia de afastamento, de fuga e de esquiva no trabalho, porém isso resulta em maior exaustão emocional. A despersonalização eleva-se na medida em que há maior utilização da estratégia de afastamento. Assim, verificou-se que quanto maior o uso de afastamento, menor o sentimento de realização no trabalho. Concluí-se que, para esses autores, existe uma relação entre organização universitária e trabalho docente que terá como resultado provável consequências de amplas proporções sobre a saúde dos trabalhadores da educação, necessitando de aprofundamento com novas investigações.

O número de alunos é sempre muito grande na área médica nas salas de aula e leva a um certo estresse; então, isso praticamente foi abolido na minha vida profissional. Eu gosto do contato com os alunos; o trabalho atual me gratifica enquanto profissional porque eu ainda oriento alunos, embora poucos e, como saí de sala de aula, aumentou minha produção científica e publicações. Isso é um aspecto muito positivo; de certa forma, eu fui cobrado a escrever esses artigos e publicá-los. (Professor 8 - PU).

Observamos que, para os entrevistados, embora a sala de aula seja reconhecidamente um lugar de realização profissional, ela é também o principal espaço de adoecimento e da sobrecarga física e mental. Há uma relação de ambivalência, de prazer e sofrimento no trabalho de professores universitários que Mancebo (2007) interpreta como um paradoxo, pois o trabalho docente constituise num lugar contraditório que suscita, a um só tempo, "sobretrabalho" e prazer. Percebe-se, nas falas, a existência de sentimentos colidentes, estando presentes aspectos positivos e negativos que concorrem para o sofrimento no trabalho.

Em nenhum momento eu quis sair de sala de aula porque o que eu gosto mesmo é de dar aula. Eu detesto burocracia, eu não suporto; o que eu gosto mesmo é de dar aula [...] Eu sofri muito porque nunca quis sair de sala de aula, nunca. (Professor 3 - PU).

Para Brant e Minayo-Gomez (2009), o sofrimento, quando visto unicamente como algo decorrente do próprio sujeito, culpabiliza o trabalhador pelas suas vivências. $\mathrm{O}$ ponto que aqui queremos realçar é o sentido que a readaptação assume na vida dos trabalhadores, individualizando o processo de adoecimento 
no trabalho, quando, em verdade, estamos tratando de um problema de saúde

coletiva. É urgente o reconhecimento do fato de que o adoecimento dos docentes acontece no âmbito (visceral) da própria dinâmica do trabalho universitário. Observamos, durante as entrevistas, que a readaptação favorece a situação adaptativa no trabalho, não propiciando a transformação do trabalho.

\section{[...] aqui há falta crônica de professores"}

Outra questão que aparece na análise das entrevistas diz respeito às condições de trabalho: quase a totalidade de entrevistados teve alguma observação sobre as condições físicas, estruturais e gerenciais da universidade ou a respeito da carga horária de trabalho dos professores readaptados e seus locais de trabalho:

A readaptação diminuiu meu número de alunos, mas aqui há falta crônica de professores, eu não tenho o descanso a cada duas horas conforme o recomendado. Hoje, por exemplo, o elevador não está funcionando e eu estaria proibida de subir pelas escadas. (Professor 5 - PU).

Segundo Lemos (2011), o panorama de precarização nas universidades abre caminho para que os professores vivenciem uma condição de trabalho deteriorada, com impacto significativo do ponto de vista físico e psíquico. Para a autora, existe um conjunto de diferentes níveis da gestão do ensino superior que terminam por afetar o cotidiano do professor, como o contingenciamento e a liberação de recursos, e ainda a definição da política de vagas de docentes e discentes. De acordo com Chauí (2003), a universidade pública carece de investimento social e político. Para isso, são necessárias condições de trabalho compatíveis com a formação universitária, que compreende, entre outras, infraestrutura de trabalho (com instalações e equipamentos que garantam o seu funcionamento), realização de concursos públicos e garantia de condições salariais dignas que permitam ao professor trabalhar em regime de tempo integral.

\section{"O pior do processo de readaptação é o tratamento dado pelos colegas"}

A discriminação é outro ponto que se destaca na análise das falas, pois os entrevistados se queixam do forte estigma que existe em relação aos professores readaptados:

A readaptação não dá conta e, da forma que está, muitos professores adoecem. $\mathrm{Na}$ verdade, deveriam colocar um programa para preservar a saúde dos professores [...] já 
foi colocado em reunião de departamento que estou causando problemas no departamento inteiro por ser readaptada, já fui acusada de estar forjando a readaptação. (Professor 5 - PU).

Sob a perspectiva da antropologia, os estudos de Goffman (1975) nos permitiram entender que a sociedade estabelece os meios de categorizar as pessoas e os atributos considerados como comuns e naturais para os membros de cada uma dessas categorias. Desse modo, quando surgem evidências de que uma pessoa tenha um atributo que a torne diferente de outras, sendo incluída numa categoria menos desejável, deixamos de considerá-la comum, colocando-a numa categoria inferior e reduzindo-a a uma condição menor. Trata-se de um estigma, especialmente quando seu efeito de descrédito é muito grande. O estigma discrimina e inferioriza. Para esse autor, a característica central e o principal desafio da situação de vida do estigmatizado é a questão da "aceitação". Aqueles que têm relações com ele (o estigmatizado) não conseguem lhe dar o respeito e a consideração que receberia em condições normais. Ao exame dos relatos dos entrevistados, percebe-se que o estigma relacionado à saúde e ao trabalho afeta a interação no cotidiano laboral e ainda pode gerar sentimento de insegurança e de impotência no trabalhador. A discriminação se transforma em estigma ao "marcar" o indivíduo com uma particularidade.

O pior do processo de readaptação é o tratamento dado pelos colegas. Eu não vejo o processo de cuidado e humanização com o readaptado; por mais que se queira, isso não existe. Você teoricamente é visto como um aleijado, mas não tem como comprovar que você é. As pessoas só entendem como incapacitado quando você perde um braço ou alguma coisa visível (Professor 7 - PU).

No cotidiano, o readaptado é recebido com desconfiança pelos colegas de trabalho e muitas vezes pela própria chefia, por não acreditarem na sua dor e sofrimento, passando ele, então, a se sentir discriminado. Estudos como o de Nunes, Brito e Athayde (2001) mostram que essa nova situação pode ocasionar sentimentos de culpa no trabalhador e de sofrimento no que diz respeito à nãoaceitação da situação de readaptação pelos colegas, uma vez que o indivíduo passa a ser considerado como "armador". Ele acaba sendo malvisto pelos colegas, pois a dor não é visível, ficando restrita a quem a sente.

Schwartz e Durrive (2007) chamam a atenção para a desestruturação dos coletivos de trabalho. Para esses autores, a complexidade dos sistemas de trabalho 
aumenta e, portanto, a importância dos coletivos também deveria aumentar. Daí

surge uma interrogação advinda das análises das falas: existe, hoje, coletivo de trabalho operando unido nas universidades? Não seria a readaptação, também, uma consequência da perda dos vínculos pessoais e coletivos no trabalho? Tocamos, assim, na dimensão coletiva do adoecimento no trabalho, pois a situação de saúde dos profissionais da educação como problema de saúde pública deve ser equacionada com a participação ativa dos trabalhadores e suas organizações, contrapondo-se à individualização do adoecimento e à culpabilização do trabalhador.

\section{"Na perícia central você é muito maltratado"}

O órgão responsável pela readaptação dos servidores estaduais do Estado do Rio de Janeiro é a Superintendência de Perícia Médica e Saúde Ocupacional (SPMSO), hoje subordinada à Secretaria de Estado de Saúde e Defesa Civil. Segundo as falas da grande maioria dos entrevistados, o processo é burocratizado e pouco humanizado:

Lá você é tratada igual a cachorro, eu tive que chegar para moça e falar assim: eu fiquei cinco anos dentro de uma faculdade de graduação e eu quero pelo menos ser tratada com educação. (Professor 3 - PU).

Na perícia central, onde você é muito maltratado, nem olham para cara da gente, chegam a ser grosseiros. (Professor 4 - PU).

[...] na perícia, começa que é um prédio sujo, imundo, o médico que me atendeu ficou no computador o tempo todo; nem olhou na minha cara. Eu cheguei às 8:00 e só fui atendida às 16:00. Aquilo lá é um horror. Você tá fragilizado; é um momento que tinha que ser bem tratado (Professor 6 - PU).

Segundo Brito et al. (2001), a maneira como é realizada a readaptação pelo órgão da perícia médica, de forma individualizada e separada de "questôes gerais do trabalho", faz com que os especialistas não analisem os processos de trabalho e sua ligação com o adoecimento. Neves e Nunes (2010) asseguram que a perícia médica sofre grandes críticas dos trabalhadores atendidos em atos periciais, por dois motivos: primeiro, porque suas ações não parecem coerentes, uma vez que se esperava do ato pericial uma atitude investigativa que buscasse os determinantes que geram adoecimento no trabalho e também um olhar médico de fato sobre a doença e sobre o doente; o segundo é o fato de o trabalhador não participar ativamente do processo decisório, sendo colocado numa postura passiva pela coerção e pelo medo. 
Em estudo realizado por Martini (2011) a respeito do processo de reabilitação de pessoas deficientes, o autor analisa algumas implicaçōes éticas e de condutas técnicas do profissional que trabalha com a reabilitação. Guardadas as devidas diferenças do trabalho do profissional de reabilitação para o trabalho da perícia médica que avalia a readaptação, o ponto que queremos realçar no referido estudo diz respeito ao "lugar" ocupado por esses profissionais, que deveria considerar seu paciente como "sujeito". Este é um ponto capital, cuja importância merece toda nossa atenção: a possibilidade de se colocar diante da fragilidade do outro sem se impor numa relação de poder. Trata-se, segundo o autor, para que não se caia nesse tipo de opressão, de considerar a "ética" como precondição da relação.

Todas essas ponderações apontam para a necessidade de maior qualificação dos profissionais da perícia médica com vistas à humanização do atendimento sob o ângulo do trabalho, o que implica transformar o próprio modo como se concebe o trabalhador, usuário do serviço - de objeto passivo a sujeito de conhecimento a respeito do seu trabalho e da sua saúde. Para Deslandes (2004), resgatar a humanidade do atendimento em saúde significa ir contra a violência - já que esta representa a antítese do diálogo, a negação do "outro" em sua humanidade seja física e psicológica, que se expressa nos "maus-tratos”; seja simbólica, que se apresenta pela dor de não ter a "compreensão de suas demandas e expectativas".

\section{Considerações finais}

De acordo com o exposto, vimos que a readaptação é um processo complexo, gerado por condições coletivas de trabalho como a sobrecarga de aulas. A saúde dos trabalhadores readaptados não pode ser reduzida apenas aos distúrbios clínicos, nos quais a causa do adoecimento fica centrada nos fatores biomédicos, não se levando em consideração a análise do contexto de trabalho que gerou o adoecimento.

Em resposta à nossa pergunta central (qual o sentido da readaptação na vida dos professores afastados de suas funções no trabalho?), confirmamos e repetimos as palavras de um professor universitário entrevistado: "A readaptação não dá conta e, da forma que está, muitos professores adoecem. Na verdade, deveriam colocar um programa para preservar a saúde dos professores". Verificamos que, embora se perceba uma carência de crítica a respeito do processo de trabalho docente em universidades como fator de adoecimento, existem apreciaçóes que vislumbram a 
necessidade de intervenções institucionais de caráter coletivo para a promoção de ambientes laborais mais saudáveis.

Quanto às possíveis diferenças existentes entre os dois grupos de professores entrevistados (Cap e Universidade), afirmamos que não foram observadas incongruências nos depoimentos entre eles, tanto no que se refere às exigências de trabalho e seus efeitos à saúde quanto à vivência da readaptação. Contudo, são necessários novos estudos que aprofundem o conhecimento a respeito das situações de trabalho de ambas as atividades docentes, buscando modificar as condiçõos laborais e seus efeitos sobre a saúde.

É necessário ainda compreender a readaptação como um dos indicadores do processo de precarização e de degradação da saúde. Diante da análise das entrevistas, ficou explícita a ausência de uma política de saúde no trabalho pensada numa perspectiva de inclusão dos readaptados. Conforme explicitam Nunes, Brito e Athayde (2001), a ausência de uma política voltada à saúde dos funcionários públicos federais, estaduais e municipais passa pelo envolvimento das equipes envolvidas nas perícias, que desconhecem o trabalho realizado. Além disso, o agravamento da saúde dos profissionais de educação necessita de inovação e aprimoramento nas metodologias de intervenção (SOUZA; BRITO, 2012).

Por fim, este trabalho nos permitiu entender, ainda que de maneira circunscrita a um estudo local, que a política de readaptação precisa de uma reformulação (ou inversão) na atual concepção da própria atividade de readaptar levada a efeito pelos órgãos públicos. Repetimos a afirmativa de que é necessário (e urgente) "a adaptação do trabalho ao homem", e não o contrário. Porquanto, assumimos como premissa básica que as distintas formas de organização e de condições de trabalho docente são os elementos-chave na determinação do quadro de saúde e readaptação no trabalho (BRITO et al., 2001). ${ }^{3}$

\section{Referências}

ALVAREZ, D. Cimento não é concreto, tamborim não é pandeiro, pensamento não é dinheiro! Para onde vai a produção acadêmica? Rio de Janeiro: Myrrha, 2004. 262p.

ASSUNCÃO, A.A.; OLIVEIRA, D.A. Intensificação do trabalho e saúde dos professores. Educ. Soc., Campinas, v.30, n.107, p.349-372, 2009.

BATISTA, J.M.; JULIANI, C.M.; AYRES, J.A. O processo de readaptação funcional e suas implicaçôes no gerenciamento em enfermagem. Rev. Latino-Am. Enfermagem. Ribeirão Preto, v.18, n.1, p.87-93, 2010. 
BOSI, A.P. A precarização do trabalho docente nas instituições de ensino superior no Brasil nesses últimos 25 anos. Educ. Soc. Campinas, v.28, n.101, p.1503-1523, 2007.

BRANT, L.C.; MINAYO-GOMEZ, C. Manifestação do sofrimento e resistência ao adoecimento na gestão do trabalho. Saude soc. São Paulo, v.18, n.2, p.237-247, 2009.

BRASIL. Lei no 8.112, de 11 de dezembro de 1990. Dispõe sobre o Regime Jurídico dos Servidores Públicos Civil da União, das autarquias e das fundações públicas federais, Brasília. Disponível em:<http://www.planalto.gov.br/ccivil_03/Leis/L8112cons.htm>. Acesso em: 01 jul. 2012.

BRITO, J.; ATHAYDE, M. Trabalho, educação e saúde: o ponto de vista enigmático da atividade. Trab. Educ. Saúde. Rio de Janeiro, v.1, n.2, p.239-266, 2003.

BRITO, J.et al. Readaptação profissional: a ponta do iceberg? In: BRITO, J. et al. (Orgs.). Trabalhar na Escola? "Só inventando o Prazer". Rio de Janeiro: IPUB, 2001, p. 163-184.

CANGUILHEM, G. O normal e o patológico. Rio de Janeiro: Forense Universitária, 1990. 307p. CARLOTTO, M.S. Síndrome de burnout e caraterísticas de cargo em professores universitários. Rev. Psicol., Organ.Trab. Brasília, v.4, n.2, p.145-162, 2004.

CARLOTTO, M.S.; CAMARA, S.G. Síndrome de Burnout e estratégias de enfrentamento em professores de escolas públicas e privadas. Psicol. educ. São Paulo, n.26, p.29-46, 2008.

CHAUI, M. A universidade pública sob nova perspectiva. Rev. Bras. Educ. Rio de Janeiro, n.24, p.5-15, 2003.

CZERESNIA, D. Canguilhem e o caráter filosófico das ciências da vida. Physis: Revista de Saúde Coletiva. Rio de Janeiro, v.20, n.3, p.709-727, 2010.

DEJOURS, C. O trabalho como enigma. In: LANCMAN, S.; SZNELWAR, L. (Orgs.). Christophe Dejours: da psicopatologia à psicodinâmica do trabalho. Rio de Janeiro: Fiocruz, 2004. p. 127-140.

DESLANDES, S. Análise do discurso oficial sobre a humanização da assistência hospitalar Ciênc. saúde coletiva. Rio de Janeiro, v.9, n.1, p.7-14, 2004.

DURAFFOURG, J. O trabalho e o ponto de vista da atividade. In: SCHWARTZ, Y.; DURRIVE, L. (Orgs.). Trabalho e ergologia: conversas sobre a atividade humana. Niterói: EdUFF, 2007. p. 47-82.

FANTINI, A.J.E.; SILVEIRA, A.M.; ROCCA, P.F. Readaptação ocupacional de servidores públicos: a experiência de uma universidade pública. Rev Med Minas Gerais. Belo Horizonte, v.20, n.2, supl. 2, p.59-65, 2010.

GASPARINI, S.M.; BARRETO, S.M.; ASSUNÇÃO, A.A. O professor, as condições de trabalho e os efeitos sobre sua saúde. Educação e Pesquisa. São Paulo, v.31, n.2, p.189-199, 2005. GILL, R. Análise do discurso. In: BAUER, M.; GASKELL, G. (Orgs.). Pesquisa qualitativa com texto, imagem e som. Petrópolis: Vozes, 2008. p. 244- 270. 
GOFFMAN, E. Estigma: notas sobre a manipulação da identidade deteriorada. Rio de Janeiro: Zahar, 1975. 158p.

GOMES, V.C.M. Readaptação profissional no serviço público federal: sentido, politica e leis. 2011. 61p. Monografia (Especialização em Saúde do Trabalhador) - Centro de Estudos da Saúde do Trabalhador, Escola Nacional de Saúde Pública, FIOCRUZ, Rio de Janeiro, 2011. GUERIN, F et al. Compreender o trabalho para transformá-lo: a prática da ergonomia. São Paulo: Edgard Blücher, 2001. 200p.

HARDT, M.; NEGRI, A. Multidão: guerra e democracia na era do império. Rio de Janeiro: Record, 2005. 530p.

LACAZ, F.A.C. Capitalismo organizacional e trabalho: a saúde do docente. Univ. Soc., Brasília, ano XIX, n.45, p.51-59, 2010.

LEMOS, D. Trabalho docente nas universidades federais: tensões e contradições. Cad. CRH. Salvador, v.24, n.spe1, p.105-120, 2011.

LUZ, M.T. Prometeu acorrentado: análise sociológica da categoria produtividade e as condições atuais da vida acadêmica. Physis: revista de Saúde Coletiva. Rio de Janeiro, v.15, n.1, p.39-57, 2005.

MANCEBO, D. Trabalho docente: subjetividade, sobre implicação e prazer. Psicol. Reflex. Crit. Rio Grande do Sul, v.20, n.1, p.74-80, 2007.

MARTINI, A. Reabilitação, ética e técnica. Ciênc. saúde coletiva. Rio de Janeiro, v.16, n.4, p.2263-2269, 2011.

MARX, K. Manuscritos econômico-filosóficos. São Paulo: Abril Cultural (Coleção Os Pensadores), 1974. p. 7-54.

MEDEIROS, A.M.; BARRETO, S.M.; ASSUNÇĀO, A.A. Professores afastados da docência por disfonia: o caso de Belo Horizonte. Cadernos Saúde Coletiva. Rio de Janeiro, v.14, n.4, p.615-624, 2006.

MINAYO GOMEZ, C. Campo da saúde do trabalhador: trajetória, configuração e transformação. In: MINAYO GÓMEZ, C. et al. (Orgs.). Saúde do trabalhador na sociedade brasileira contemporânea. Rio de Janeiro: Fiocruz, 2011. p.23-34.

MINAYO, M.C.S. O desafio do conhecimento: pesquisa qualitativa em saúde. São Paulo: Hucitec, 2004.

NEVES, M.Y.; SILVA, E.S. A dor e a delícia de ser (estar) professora: trabalho docente e saúde mental. Estud. pesqui. psicol., v.6, n.1, p.63-75. 2006.

NEVES, R.F.; NUNES, M.O. Da legitimação a (res) significação: o itinerário terapêutico de trabalhadores com LER/DORT . Ciênc. saúde coletiva. Rio de Janeiro, v.15, n.1, p.211$220,2010$. 
NUNES, B.O.; BRITO,J.C.; ATHAYDE,M. Readaptação profissional e produção de sentido no trabalho de merendeiras e serventes. In: BRITO, J. et al. (Orgs.). Trabalhar na escola? Só inventando o prazer. Rio de Janeiro: Ipub-Cuca, 2001. p.185-214.

ODDONE, I. et al. Ambiente de trabalho: a luta dos trabalhadores pela saúde. São Paulo: Hucitec, 1986. 133p.

PORTOCARRERO, V. As ciências da vida: de Canguilhem a Foucalt. Rio de Janeiro: Fiocruz, 2009. 259p.

QUADROS, A.L. et al. A percepção de professores e estudantes sobre a sala de aula de ensino superior: expectativas e construção de relações no curso de química da UFMG. Ciênc. educ. Bauru, v.16, n.1, p.103-114, 2010.

RAMOS, M.Z.; TITTONI, J.; NARDI, H.C. A experiência de afastamento do trabalho por adoecimento vivenciada como processo de ruptura ou continuidade nos modos de viver. Cad. psicol. soc. trab. São Paulo, v.11, n.2, p.209-221, 2008.

RIO DE JANEIRO. Decreto no 2.479, de 8 de março de 1979. Dispóe sobre o Estatuto dos Funcionários Públicos Civis do Poder Executivo do Estado do Rio de Janeiro. Diário Oficial do Estado do Rio de Janeiro, Rio de Janeiro, 09 mar.1979. Disponível em: http:// www.jusbrasil.com.br/legislacao/90539/decreto-2479-79-rio-de-janeiro-rj\#art0. Acesso em: 30 set. 2012.

SAMPAIO, M.M.; MARIN, A.J. Precarização do trabalho docente e seus efeitos sobre as práticas curriculares. Educ. Soc. Campinas, v.25, n.89, p.1203-1225, 2004.

SANTOS, B.S. Um discurso sobre as ciências. Porto: Afrontamento, 1997. 58p.

SCHWARTZ, Y.; DURRIVE, L. Trabalho e ergologia: conversas sobre a atividade humana. Niterói: EdUFF, 2007. 309p.

SOUSA, I.F.; MENDONCA, H. Burnout em professores universitários: impacto de percepções de justiça e comprometimento afetivo. Psic. Teor. e Pesq. Brasília, v.25, n.4,p 499-508, 2009.

SOUZA, K.R.; BRITO, J.C . Sindicalismo, condições de trabalho e saúde: a perspectiva dos profissionais da educação do Rio de Janeiro. Ciênc. saúde coletiva. Rio de Janeiro, v.17, n.2, p.379-388, 2012.

TOLDRÁ, R.C. et al. Facilitadores e barreiras para o retorno ao trabalho: a experiência de trabalhadores atendidos em um Centro de Referência em Saúde do Trabalhador - SP, Brasil. Rev. bras. Saúde ocup. São Paulo, v.35, n.121, p.10-22, 2010.

UNIVERSIDADE DO ESTADO DO RIO DE JANEIRO. Deliberação no 56, de 18 de outubro de 2010. Dispõe sobre o Programa de Incentivo à Produção Científica, Técnica e Artística - PROCIÊNCIA. Disponível em: http://www.sr2.uerj.br/sr2/depesq/procienc/ deliberacao056-2010.html. Acesso em: 08 mar. 2013. 
VIEIRA, E.M.F.; VAN BELLEN, H.M.;FIALHO, F.A.P. Universidade em tempo de mudança. Cad. EBAPE.BR. Rio de Janeiro, v.4, n.3, p.01-07, 2006.

WISNER, A. Questôes epistemológicas em ergonomia e em análise do trabalho. In: DANIELlOU, F. (Org). A ergonomia em busca de seus princípios: debates epistemológicos. São Paulo: Edgar Blücher, 2004. p. 29-56.

\section{Notas}

${ }^{1} \mathrm{O}$ texto deste artigo é resultado da pesquisa de conclusão do curso de especialização em saúde do trabalhador (Ensp/Fiocruz), e não há conflito de interesses relacionados a esse estudo.

${ }^{2}$ O Colégio de Aplicação da UERJ (CAP-UERJ), denominado Instituto de Aplicação Fernando Rodrigues da Silveira, é uma instituição de ensino pública tendo por finalidade a formação docente inicial e continuada, em parceria com outras unidades acadêmicas da Universidade, bem como a promoção de educação básica de qualidade e de atividades de pesquisa em ensino e educação (Referência obtida no website CAP-UERJ. Disponível em: http://www.cap.uerj.br/site. Acesso em: 31 jul 2012.

${ }^{3}$ A.P.S. Arbex participou da concepção do estudo, realizou a pesquisa de campo e contribuiu com a redação do artigo. K.R. Souza participou da concepção do estudo, orientou a pesquisa de campo e contribuiu com a redação do artigo. A.L.O. Mendonça contribuiu com a redação do artigo e realizou sua revisão crítica. 


\section{Abstract}

\section{Teaching, readjustment and health: the experience of teachers at a public university in Brazil}

In this paper we aimed at analyzing, from the perspective of workers themselves and under the methodological approach of qualitative research, the meanings of readjustment in the lives of professors at a public university. Eight readapted professors with stable relationship with the university and two others from Application School have participated in this study. As for the discussion of the material, we have chosen the method of discourse analysis, aiming to interpret from their own speech and experience, how the professors deal with the fact that they are readjusted. The main categories of empirical results from the speech analyzes were: "You have to catch up with your papers to be published and teach and prepare lessons, as well" "The readjustment was favorable to my health condition just because I've quit classes", "There is chronic lack of professors here", "The worst in the process of readjustment is the treatment you receive from colleagues", "In central expertise you are very badly treated". It was concluded that the functional readjustment is a process generated by collective work conditions, for example, the overhead of classes, which requires the need for collective character of institutional interventions to promote healthier working environments.

Key words: readjustment to work; teaching; health worker; classroom; medical expertise. 